\title{
QUALIDADE DE TANGERINA 'PONCÃ' MINIMAMENTE PROCESSADA, ARMAZENADA A $5^{\circ} \mathrm{C}$
}

\author{
Quality of fresh-cut 'Poncã' Tangerine, stored at $5^{\circ} \mathrm{C}$
}

\author{
Daniella Moreira Pinto ${ }^{1}$, Eduardo Valério de Barros Vilas Boas², Clarissa Damiani ${ }^{3}$
}

\begin{abstract}
RESUMO
Com o presente trabalho, objetivou-se analisar o comportamento da Tangerina 'Poncã' minimamente processada armazenada a $5^{\circ} \mathrm{C}$. O experimento foi executado no Laboratório de Pós-Colheita de Frutas e Hortaliças do Departamento de Ciência dos Alimentos da Universidade Federal de Lavras - MG. As frutas foram lavadas com detergente neutro e sanificadas com hipoclorito de sódio a 200 ppm por 15 minutos, descascadas, embaladas e resfriadas imediatamente a $5^{\circ} \mathrm{C}$. Foi utilizado um delineamento inteiramente casualizado simples, com 3 repetições e 3 frutas por parcela experimental. A influência de 5 níveis do fator tempo (0, 3, 6, 9 e 12 dias) foi avaliada. A qualidade das frutas foi analisada a partir das seguintes variáveis: perda de massa, rendimento em suco, concentração de $\mathrm{O}_{2}{\mathrm{e} \mathrm{CO}_{2}}$ no interior das embalagens, valores $\mathrm{L}^{*}, \mathrm{a}^{*} \mathrm{e} \mathrm{b*}, \mathrm{pH}$, acidez titulável, sólidos solúveis, $\beta$-caroteno e vitamina $\mathrm{C}$. A temperatura de $5^{\circ} \mathrm{C}$ foi adequada no armazenamento de Tangerina 'Poncã' minimamente processada, baseado nas pequenas modificações na cor, acidez titulável, sólidos solúveis, perda de massa e rendimento do suco, embora, perdas nos teores de vitamina C (34,07\%) e $\beta$-caroteno $(42,75 \%)$ tenham sido observadas.
\end{abstract}

Termos para indexação: Citrus reticulata Blanco, processamento mínimo, refrigeração.

\section{ABSTRACT}

The objective of the work was to analyze the behavior of the fresh-cut 'Poncã' Tangerine stored $5^{\circ} \mathrm{C}$. The experiment was carried out in the Postharvest Fruit and Vegetables Laboratory of the Food Science Department / Federal University of Lavras - Brazil. The fruit were washed with neutral detergent and sanitized with sodium hipochlorite 200ppm for 15 minutes, peeled, packed and immediately cooled at $5^{\circ} \mathrm{C}$. It was used a fully randomly design, with 3 replications and 3 fruits per plote. The influence of 5 levels of the factor time $(0,3,6,9$ and 12 days) was evaluated. The quality of the fruit was analyzed based in the following variable: mass loss, juiciness, concentration of $\mathrm{O}_{2}$ and $\mathrm{CO}_{2}$ into the packages, $\mathrm{L} *, \mathrm{a}^{*}$ and $\mathrm{b} *$ values, $\mathrm{pH}$, titratable acidity, soluble solids, $\beta$-carotene and vitamin $\mathrm{C}$ content. The temperature of $5^{\circ} \mathrm{C}$ was indicated to the storage of fresh-cut 'Poncã' tangerine based in minor changes in color, titratable acidity, soluble solids, mass loss and juiciness although losses in vitamin $\mathrm{C}(65,93 \%)$ and $\beta$-carotene $(42,75 \%)$ have been observed.

Index terms: Citrus reticulata Blanco, fresh-cut, refrigeration.

(Recebido em 3 de abril de 2006 e aprovado em 28 de julho de 2006)

\section{INTRODUÇÃO}

As tangerinas constituem o segundo grupo de frutos cítricos mais importantes na citricultura mundial, ocupando, possivelmente, a maior faixa de adaptação climática entre os citrus cultivados, uma vez que são plantas igualmente tolerantes a níveis altos e baixos de temperatura ambiente. As árvores que produzem essa fruta têm tamanho médio e são espinhosas, com copa cheia e arredondada, formada por folhas pequenas de cor verdeescura. As flores, de perfume muito suave, são brancas e bem pequenas (REIS et al., 2000).

Dentre as cultivares de tangerina, encontra-se a 'Poncã', a qual é originária da Índia e, devido às suas boas qualidades, difundiu-se rapidamente através do oriente, ocidente e, chegou ao Brasil em 1947/48 (HODGSON, 1967).
Entretanto, algumas pessoas não consomem essa fruta por ela deixar um forte odor residual nas mãos ao descascá-las. Como uma das alternativas de resolução deste problema, o processamento mínimo veio como aliado para garantir, ao máximo, a conveniência e qualidade esperada pelo consumidor moderno.

Frutas e hortaliças minimamente processadas são definidas como sendo produtos que passam por operações como seleção, lavagem, descascamento e corte, os quais eliminam as partes não comestíveis dos mesmos, como casca, talos e sementes, seguida do corte em tamanhos menores e prontos para consumo imediato ( $100 \%$ aproveitável), sem que o vegetal perca a condição de produto ainda fresco, com qualidade e garantia de sanidade.

\footnotetext{
${ }^{1}$ Ciências Biológicas, doutoranda do Departamento de Ciência dos Alimentos da Universidade Federal de Lavras/UFLA - Cx. P. 3037 - $37200-000$ Lavras, MG - daniella25@bol.com.br

Engenheiro Agrônomo, Prof. Dr. do Departamento Ciência dos Alimentos da Universidade Federal de Lavras/UFLA - Cx. P. 3037 - $37200-000$ Lavras, MG - evbvboas@ufla.br

${ }^{3}$ Engenheira de Alimentos, doutoranda do Departamento de Ciência dos Alimentos da Universidade Federal de Lavras/UFLA - Cx. P. 3037 - $37200-000$ Lavras, MG - damianiclarissa@bol.com.br
} 
O segmento de produtos minimamente processados apresentou, nos últimos anos, um grande desenvolvimento, motivado pela aceitação dos produtos que oferecem conveniência, segurança e a certeza de produto cada vez mais necessário à boa saúde.

A manutenção da qualidade e extensão da vida útil de frutas minimamente processadas depende de um rígido respeito à cadeia de frio e de operações higiênico-sanitárias adequadas. Tanto o processamento como o armazenamento das frutas deve ser realizado a baixas temperaturas. Quanto maior a temperatura, maior a taxa respiratória e, conseqüentemente, menor a vida útil do produto.

A utilização do armazenamento refrigerado para frutas minimamente processadas se baseia na idéia de que as baixas temperaturas reduzem a taxa de respiração, retardam o crescimento da maioria dos microrganismos e as deteriorações, como o escurecimento e o amolecimento. Em geral, estes devem ser armazenados entre $0^{\circ} \mathrm{C}$ e $5^{\circ} \mathrm{C}$ para manutenção da qualidade, segurança e vida de prateleira (VILAS-BOAS, 2004).

Com o presente trabalho, visou-se analisar o comportamento da Tangerina 'Poncã' minimamente processada, armazenada a $5^{\circ} \mathrm{C}$, frente às principais mudanças físicas e químicas que ocorreram durante 12 dias de armazenamento.

\section{MATERIAIS E MÉTODOS}

As tangerinas foram adquiridas no comércio local de Lavras/MG, transportadas para o Laboratório de Póscolheita de Frutas e Hortaliças do Departamento de Ciência dos Alimentos da Universidade Federal de Lavras, Lavras/ MG e levadas para a sala de processamento mínimo, previamente lavada e sanificada com hipoclorito de sódio a $300 \mathrm{ppm}$, juntamente com todos os materiais a serem utilizados. No local do processamento, as tangerinas foram lavadas com detergente neutro, sanificadas com hipoclorito de sódio $200 \mathrm{ppm}$ por 15 minutos em água refrigerada $\left(15^{\circ} \mathrm{C}\right.$ e pH 7,0) e armazenadas durante 6 horas sob refrigeração $\left(18^{\circ} \mathrm{C}\right)$ até o início do processamento. Após este período, as tangerinas foram descascadas e acondicionados em embalagens plásticas rígidas de polipropileno com tampa, com dimensões de $15,0 \mathrm{~cm}$ de comprimento $\mathrm{x} 11,5 \mathrm{~cm}$ de largura $\mathrm{x} 4,5 \mathrm{~cm}$ de altura, contendo, em cada, três frutos. $\mathrm{O}$ produto embalado foi armazenado em câmara fria a $5^{\circ} \mathrm{C} \pm$ $1^{\circ} \mathrm{C} / 95 \% \mathrm{UR}$, por um período de 12 dias.

A cada três dias $(0,3,6,9,12$ dias $)$, foram analisadas as seguintes variáveis: a concentração de $\mathrm{O}_{2}$ e $\mathrm{CO}_{2}$ foi monitorada através do septo de silicone, colocado na superfície da tampa plástica da embalagem, por onde se retirava alíquota da atmosfera interna, com o auxílio do analisador de gases PBI Dansensor e expressas em porcentagem; a perda de massa foi calculada pela diferença entre a massa inicial das tangerinas embaladas no dia do processamento e a massa obtida em cada intervalo de 3 dias, utilizando balança semi-analítica Mettler, modelo PC2000 e expressa em porcentagem; a coloração foi determinada com o colorímetro Minolta CR-400, no modo CIE L*, $\mathrm{a}^{*} \mathrm{e} \mathrm{b}^{*}$, sendo que as leituras foram feitas nas três frutas, por embalagem, perfazendo um total de, aproximadamente, 30 leituras por repetição; o rendimento do suco foi calculado através do peso do suco extraído das três frutas de cada repetição, multiplicado por 100 e dividido pelo respectivo peso das frutas inteiras, utilizando balança semi-analítica Mettler modelo PC 2000; o pH foi determinado com o auxílio do pHmetro TECNAL (Tec 3MP), segundo AOAC (1992); a acidez titulável foi realizada por titulação com solução de $\mathrm{NaOH} 0,1 \mathrm{~N}$, tendo como indicador fenolftaleína, de acordo com Instituto Adolf Lutz (1985) e os resultados expressos em porcentagem de ácido cítrico; os sólidos solúveis foram determinados por refratometria, utilizando refratômetro digital ATAGO PR 100 com compensação de temperatura automática a $25^{\circ} \mathrm{C}$ e os resultados expressos em graus Brix, conforme a AOAC (1992); o teor de vitamina $C$ foi determinada segundo Brune (1966) e a concentração de $\beta$-caroteno foi determinado de acordo com metodologia utilizada por Nagata \& Yamashita (1992).

O delineamento experimental utilizado foi inteiramente casualizado (DIC) simples, com 3 repetições e 3 frutas por parcela experimental. Foi avaliada a influência de 5 níveis do fator tempo (0, 3, 6, 9 e 12 dias). As análises estatísticas foram realizadas com o auxílio do programa SISVAR (FERREIRA, 2000).

\section{RESULTADOS E DISCUSSÃO}

Durante os 12 dias de armazenamento a $5^{\circ} \mathrm{C}$, não houve diferenças significativas para o valor $\mathrm{a}^{*}$ (com média de 3,9$)$, para o $\mathrm{pH}$ (com média de 4,0) e concentração de $\mathrm{O}_{2}$ $(21 \%)$ e $\mathrm{CO}_{2}(0,03 \%)$ no interior das embalagens.

$\mathrm{O}$ valor $\mathrm{a}^{*}$ indica uma variação de cor do verde ao vermelho. A permanência desse valor, no decorrer do experimento, era esperado, uma vez que a Tangerina 'Poncã' encontrava-se descascada. Caso contrário esse valor poderia sofrer modificações significativas, pela perda da clorofila na casca, durante o armazenamento.

Em relação ao $\mathrm{pH}$, este se manteve constante e condizente com os observados por Rufini \& Ramos (2002), os quais, ao estudarem a influência do raleio manual na 
qualidade de Tangerinas Poncã, encontraram valores médios de $\mathrm{pH}$ em torno de 3,86 nos frutos que não foram submetidos ao raleio manual. A concentração estável de $\mathrm{O}_{2}$ e $\mathrm{CO}_{2}$ dentro da embalagem mostrou que esta não foi barreira para as trocas gasosas.

A cor é provavelmente um fator determinante na aquisição da fruta pelo consumidor, uma vez que este não experimenta a fruta antes da compra, associando a cor favorável ao paladar. Conforme a Figura 1, observa-se que o valor $\mathrm{L}^{*}$ decresceu pouco até o $3^{\circ}$ dia de armazenamento, a partir do qual aumentou até o final. No dia do processamento, esse valor era de 57,02, chegando a 53,86 no $3^{\circ}$ dia, e voltando a um valor de 58,54 no último dia de armazenamento.

O valor "b", que representa a coloração do azul ao amarelo, decresceu significativamente (figura 1), no transcorrer dos 12 dias (19,55 para 15,14), anunciando uma perda de coloração amarela, a qual é freqüente em produtos minimamente processados, devido aos cortes sofridos, podendo ocorrer oxidação enzimática, através da interação entre substratos e enzimas e, também, por perdas de vitaminas, principalmente os carotenóides que conferem coloração amarelada.

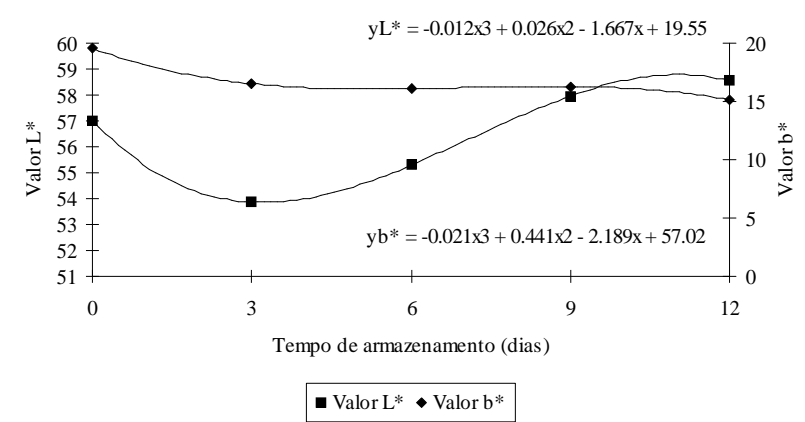

FIGURA 1 - Valores médios de $\mathrm{L}^{*}$ e $\mathrm{b}^{*}$ em Tangerina 'Poncã' minimamente processada, armazenadas sob refrigeração $\left(5^{\circ} \mathrm{C}\right)$.

A acidez titulável (AT), expressa em \% de ácido cítrico, nas tangerinas 'Poncã' minimamente processadas, variou, significativamente (Figura 2), durante o armazenamento, ficando bem abaixo do teor encontrado por Figueiredo (1991) em tangerinas 'Poncã' in natura, produzidas no Estado de São Paulo (0,85\%), porém condizente com os estudos realizados por Pio et al. (2001), ao estudarem as características do fruto da variedade 'SpanAmericana' (tipo de poncã com maturação precoce), ou seja, valores de acidez entre 0,4 a $0,8 \%$ de ácido cítrico.

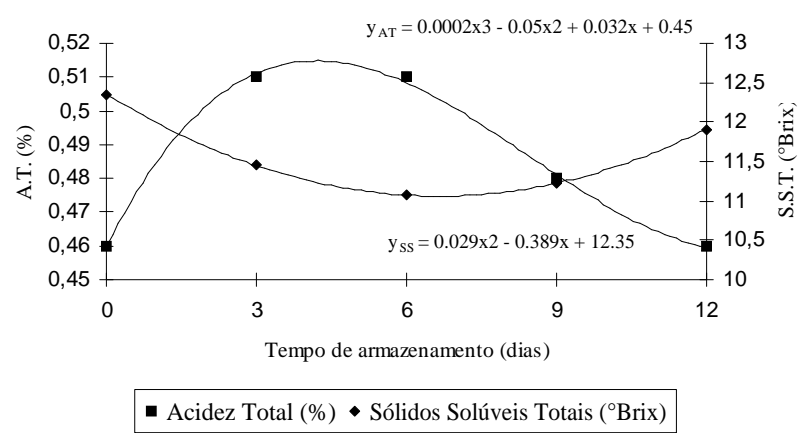

FIGURA 2 - Valores médios de acidez titulável e sólidos solúveis totais em Tangerina 'Poncã' minimamente processada, armazenada sob refrigeração $\left(5^{\circ} \mathrm{C}\right)$.

Observa-se um acréscimo até o $6^{\circ}$ dia $(0,46 \%$ para $0,51 \%)$, decaindo seu valor a partir de então $(0,46 \%)$. Esse fenômeno pode ser explicado pela injúria sofrida durante o processamento, pelos tecidos vegetais, que ativam uma série de respostas fisiológicas e bioquímicas complexas, segundo Chitarra (2000) e, pela capacidade tampão de certos sucos, os quais permitem que ocorram uma oscilação na AT, sem variações apreciáveis no pH (CHITARRA \& CHITARRA, 1990).

O teor de sólidos solúveis totais (SST) apresentou uma ligeira variação $\left(12,35^{\circ}\right.$ Brix para $11,91^{\circ}$ Brix $)$, decrescendo seu valor até o $9^{\circ}$ dia, mas tornando a elevar-se a partir do $10^{\circ}$ dia (figura 2), devido às mudanças no metabolismo. Entretanto, o teor encontrado durante todo o processamento está de acordo com os valores encontrados por Rufini \& Ramos (2002), ao estudarem a qualidade dos frutos da tangerina Poncã, os quais observaram valores médios de $12,78^{\circ}$ Brix e bem maior ao descrito por Figueiredo (1991) em tangerinas 'Poncã' in natura $\left(10,8^{\circ}\right.$ Brix $)$.

A perda de massa e o rendimento do suco também foram afetados pelo armazenamento (Figura 3). O principal fator responsável pela perda de massa é a transpiração. Esta influencia diretamente no processo de perda de qualidade dos produtos minimamente processados, sendo afetada pela umidade relativa (UR) no armazenamento, que deve variar de $80 \%$ a $95 \%$ conforme o fruto. No experimento, aqui relatado, a UR da câmara de refrigeração foi de $95 \%$.

Observou-se que houve um aumento na perda de massa (Figura 3), durante o armazenamento, chegando a um valor de 0,3\%. Segundo Chitarra \& Chitarra (1990), somente perdas de massa na ordem de $3 \%$ a $6 \%$ são suficientes para causar um marcante declínio na qualidade do produto. 


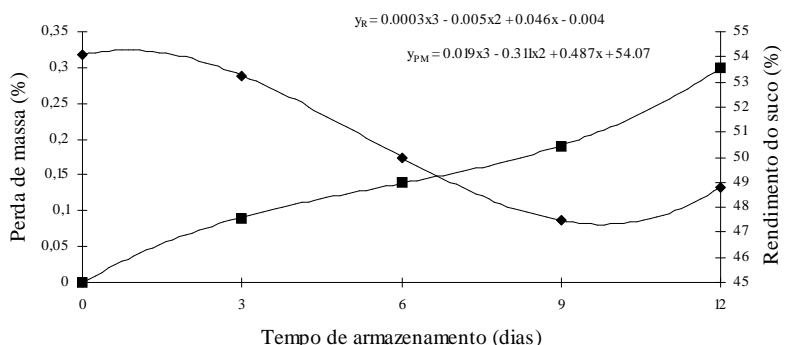

- Perda de Massa (\%) • Rendimento do Suco (\%)

FIGURA 3 - Valores médios de perda de massa e rendimento do suco em Tangerina 'Poncã' minimamente processada, armazenada sob refrigeração $\left(5^{\circ} \mathrm{C}\right)$.

O rendimento do suco (Figura 3) decresceu, significativamente, até o $9^{\circ}$ dia de armazenamento (54,07\% para $47,47 \%$ ), elevando-se, pouco, no período final $(48,81 \%)$. Contudo, o rendimento do suco aqui encontrado foi muito maior do que por Figueiredo (1991) em tangerinas Poncã in natura, produzidas no Estado de São Paulo (43\%) e por Pio et al. (2001), ao avaliarem as características de tangerinas 'Span Americana', no período de 1994 a 1996, no município de Cordeirópolis SP $(30$ a $41,3 \%)$.

A importância nutricional das frutas cítricas é relevante, principalmente, devido ao seu teor de vitamina $\mathrm{C}$, contudo, o processamento mínimo, pode favorecer essa perda. Os teores de vitamina $\mathrm{C}$ e $\beta$-caroteno (Figura 4) decresceram, significativamente, durante o armazenamento. A vitamina $C$ variou de $59,08 \mathrm{mg} / 100 \mathrm{~g}$ para $38,95 \mathrm{mg} / 100 \mathrm{~g}$

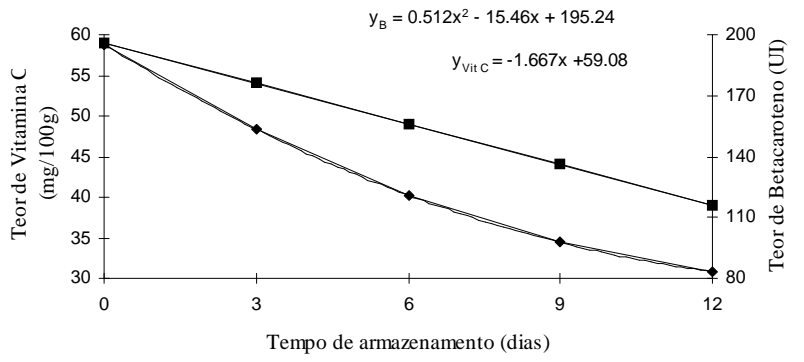

- Vitamina C (mg/100g) • Betacaroteno (UI)

FIGURA 4 - Valores médios de vitamina $C$ e $\beta$ caroteno em Tangerina 'Poncã' minimamente processada, armazenada sob refrigeração $\left(5^{\circ} \mathrm{C}\right)$. de suco, ocorrendo uma queda de aproximadamente $35 \%$, entretanto condiz com Ting \& Attaway (1971), os quais relatam um teor de 20 a $50 \mathrm{mg} / 100 \mathrm{ml}$ de suco de tangerina in natura.

Com relação ao teor de $\beta$-caroteno, observou-se um decréscimo significativo (195,24 UI para 83,48 UI), ocorrendo uma perda próximo de $43 \%$, confirmando a redução no valor $b^{*}$ (Figura 1 ).

\section{CONCLUSÕES}

A temperatura de $5^{\circ} \mathrm{C}$ foi adequada no armazenamento de Tangerina 'Poncã' minimamente processada, durante 12 dias de armazenamento, baseado nas pequenas modificações que ocorreram na cor, como aumento do valor $\mathrm{L}^{*}$ e diminuição do valor $\mathrm{b}^{*}$; variação mínima na acidez titulável e nos sólidos solúveis; na perda de massa $(0.3 \%)$ e no rendimento do suco.

Contudo, o valor nutricional da Tangerina 'Poncã' minimamente processada, no que diz respeito aos teores de vitamina $C$ e $\beta$-caroteno, foi afetado, ocorrendo redução de $34,07 \%$ e $42,75 \%$, respectivamente.

\section{REFERÊNCIAS BIBLIOGRÁFICAS}

ASSOCIATION OF OFFICIAL ANALYTICAL CHEMISTRY. Official methods of analysis of the Association of Official Analytical Chemistry. 12. ed. Washington, 1992. $1015 \mathrm{p}$.

BRUNE, W. Sobre o teor de vitamina $\mathrm{C}$ em mistaceas. Ceres, Vicosa, v. 13, n. 14, p. 418-425, 1966.

CHITARRA, M. I. F. Processamento mínimo de frutas e hortaliças. Lavras: UFLA/FAEPE, 2000. 113 p.

CHITARRA, M. I. F.; CHITARRA, A. B. Pós-colheita de frutos e hortaliças: fisiologia e manuseio. Lavras: ESAL/ FAEP, 1990. $320 \mathrm{p}$

FERREIRA, D. F. Análises estatísticas por meio do SISVAR para windows versão 4.0. In: REUNIÃO ANUAL DA REGIÃOBRASILEIRA DA SOCIEDADE INTERNACIONAL DE BIOMETRIA, 45., 2000, São Carlos. Programa e Resumo... São Carlos: UFSCar, 2000. p. 235.

FIGUEIREDO, J. O. de. Variedades copa de valor comercial. In: RODRIGUEZ, O.; VIÉGAS, F.; POMPEU JUNIOR, J.; AMARO, A. A. Citricultura brasileira. 2. ed. Campinas: Fundação Cargill, 1991. v. 1, p. 228-264. 
HODGSON, R. W. Horticultural varieties of citrus. In: REUTHER, W.; WEBBER, H. J.; BATCHELOR, L. D. The citrus industry. Berkelly: University of California, 1967. v. 1, cap. 4, p. 431-591.

INSTITUTO ADOLFO LUTZ. Normas analíticas do Instituto Adolfo Lutz: métodos químicos e físicos para análise de alimentos. 3. ed. São Paulo, 1985. v. 1, 370 p.

NAGATA, M.; YAMASHITA, I. Simple method for simultaneous determination of chlorophyll and carotenoids in tomato fruit. Nippon Shokuhin Kogyo Gakkaishi, Tokio, v. 39, n. 10, p. 925-928, 1992.

PIO, R. M.; MINAMI, K.; FIGUEIREDO, J. O. Características do fruto da variedade 'Span Americana' (Citrus reticulata Blanco): uma tangerina tipo 'poncã' de maturação precoce. Revista Brasileira de Fruticultura, Jaboticabal, v. 23, n. 2, ago. 2001.
REIS, J. M. R.; LIMA, L. C.; VILAS-BOAS, E. V. B.; CHITARRA, A. B. Relação entre o grau de coloração da casca e algumas características de qualidade de tangerina Ponkan .Revista Ciência e Agrotecnologia, Lavras, v. 24, p. 182-186, dez. 2000.

RUFINI, J. C. M.; RAMOS, J. D. Influência do raleio manual sobre a qualidade dos frutos da tangerineira 'Poncã' (Citrus reticulata Blanco). Revista Ciência e Agrotecnologia, Lavras, v. 26, n. 3, p. 505-515, maio/jun. 2002.

TING, S. V.; ATTAWAY, J. A. Citrus fruits. Biochemistry of Fruits and their Products, London, v. 2, p. 107-169, 1971.

VILAS-BOAS, E. V. B. Frutas minimamente processadas: banana. In: ENCONTRO NACIONAL SOBRE PROCESSAMENTO MÍNIMO DE FRUTAS E HORTALIÇAS, 3., 2004, Viçosa. Palestras, Resumos e Oficinas... Viçosa: UFV, 2004. 